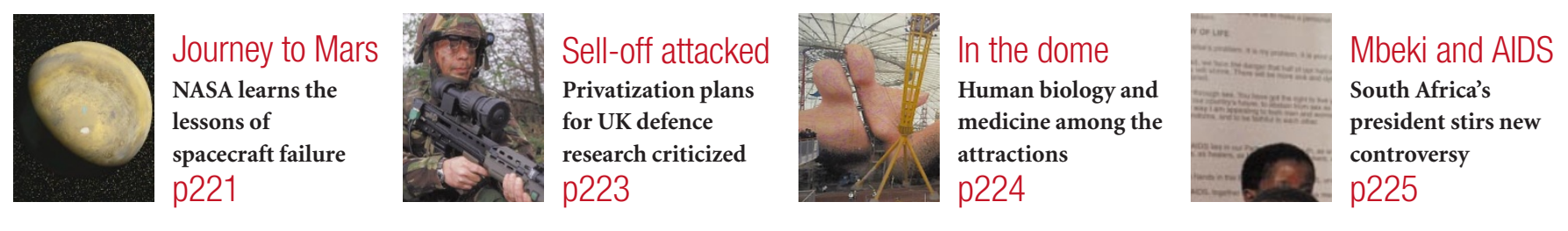

\title{
Alliance of US labs plans to build map of cell signalling pathways
}

\section{Munich}

A prominent US cell biologist is seeking funds for a multi-laboratory, multidisciplinary initiative to map how molecules in a cell interact with each other in response to internal and external signals.

The project is being launched by Alfred Gilman, who won the 1994 Nobel prize in physiology or medicine for his work on the role of proteins in signal transduction. Called the Alliance for Cellular Signalling (AFCS), it would include systems engineers, biologists and informaticists, and is seen as a step towards the creation of a 'virtual cell'.

"The research community is doing a good job of describing signalling molecules and seeing how they interact, but we now need to put [the data] together in a large collaboration so that we can address the big question of how they all work together as a system," says Gilman. "Because of the availability of complete genome sequences, we can now approach the problem in way that is not biased towards particular proteins.'

AFCS aims to identify the proteins that make up the signalling pathways in two types of mouse cell, the B lymphocyte (a cell of the immune system) and the myocyte (a heart cell). It also intends to assess the time-dependent flow of information through the systems in both normal and pathological states. Finally, it seeks to process this information and create theoretical models to describe cellular signalling.

Gilman, a professor of pharmacology at the University of Texas Southwestern Medical Center, has won support for the project from many key US cell-signalling researchers — nearly 40 top scientists have agreed to help to develop the project.

The AFCS would cost around US $\$ 10$ million a year to run, and would have two major components. First, it would create a network of around seven laboratories at academic sites across the United States, including the University of Texas Southwestern Medical Center at Dallas, the California Institute of Technology, and the University of California at San Diego and San Francisco.

These would generate information about signalling pathways in the two systems. Their research efforts would be directed by two committees, whose chairs and members have already been chosen, as have the laboratory directors.

Much of the work would involve largescale screening of protein-protein interactions, and would identify research leads that scientists elsewhere can follow up.

"We are not creating this big collaboration to dominate the field of cellular signalling," says Gilman. "Rather, we are trying to catalyse research in individual laboratories so that we can fill in the gaps in the signalling pathways."

He adds that alliance laboratories would not have privileged access to leads generated by the big screens they would undertake, as the information would be posted immediately on the Internet.

Scientists in the alliance laboratories have agreed to forgo most publishing and all commercial rights to their work, and pledge to

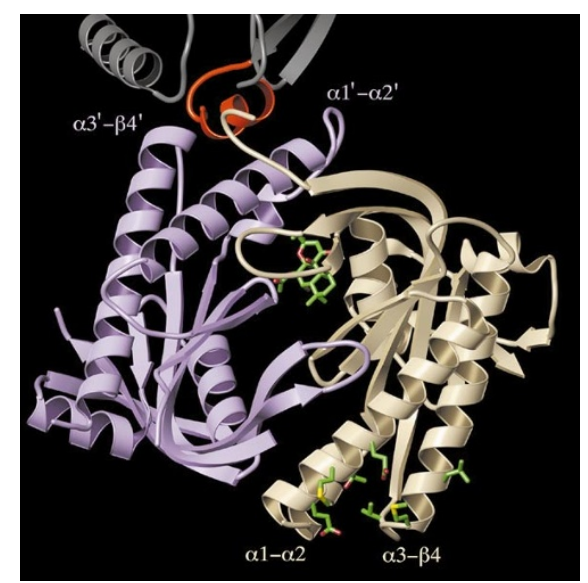

Small talk: adenylyl cyclase is one of the key molecules involved in cell signalling.

freely provide other researchers with their reagents and mutants. "It's a new way of doing business that requires collaborators

\section{Scientists reel after Indian cyclone}

\section{New Delhi}

India's worst cyclone this century, which ripped through the eastern state of Orissa on 29 October, flooded a nuclear accelerator lab, wiped out a botanical garden, and crushed the very radar system used to detect it.

The cyclone is also feared to have destroyed rice germplasm in the gene bank of the Central Rice Research Institute (CRRI) in Cuttack. One official estimates the damage at US\$8-10 million.

CRRI's rice gene bank had about 22,000 collections. Of these, the 5,000 or so varieties grown in experimental plots were washed away, says CRRI director Shanti Bhushan Lodh.

The viability of the remaining seeds, which are stored in a refrigerated module at $4{ }^{\circ} \mathrm{C}$, is not known. But Rajendra Singh Paroda, head of the Indian Council of Agricultural Research, says: "We expect the seeds to be unharmed, as no water had entered the module."

Harder to replace will be the losses at the
Regional Plant Resources Centre, one of the world's largest botanical gardens, on the outskirts of the state capital, Bhubaneswar.

Its director, Premananda Dash, says the centre lost its entire germplasm of bamboo, palms, cacti and medicinal plants, and its collection of ferns, ornamental trees, shrubs and trees. "More than 20,000 tissue cultures have been swept away and equipment worth \$1 million lost," he says. "It will take eight to ten years to restore the centre."

The lost radar system was located at Paradip port. It was one of three warning radars on the east coast of India operated by the Indian Meteorological Department with the capability of detecting cyclone formations up to $400 \mathrm{~km}$ away.

At the Institute of Nuclear Physics in Bhubaneswar, the experimental hall of the 3-MeV 'pellatron' accelerator was flooded. The institute's library has disappeared, but Valangiman Ramamurthi, secretary to the Department of Science and Technology, says that the accelerator "is intact". K. S. Jayaraman 
to act altruistically," says Gilman. At present, Gilman plans to keep alliance laboratories based in North America, and plans regular teleconferencing using the broad-band Internet 2 to link people and computers at the various centres. Collaborators cannot be spread across too many time zones, he says, and Internet 2 does not yet exist outside the United States.

But he hopes that the international community can become involved in the second part of AFCS's work, the creation of 'molecule pages' describing detailed properties of proteins involved in the signalling pathways.

These pages, which will be peer reviewed by an editorial board and regularly updated, will be created as a web database - or what Gilman calls a "virtual journal" - by 'alliance members'. These are currently being sought. AFCS's steering group sent out letters to the research community last month, and has so far received 110 replies, 10 per cent from non-US scientists.

AFCS plans to develop tools for data management and analysis that must also be flexible enough to accommodate a variety of systems-modelling techniques.

Gilman hopes to raise half the running

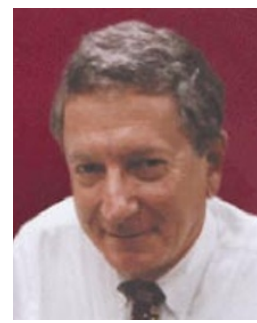

Gilman: creating a 'virtual journal'. costs from a new grant programme of the National Institutes of Health's National Institute for General Medical Sciences, which is designed for large-scale interdisciplinary approaches to problems in biology. The grant proposal has reached the second round of assessment, and a decision is expected in spring.

Using a model similar to that of the SNP consortium (see Nature 398, 545; 1998), Gilman wants to raise the other half of the money from a consortium of pharmaceutical companies. He says these "will in any case benefit from the information about signalling systems, which are important drug targets". He is asking for an annual contribution of $\$ 500,000$ from each commercial participant.

Tony Pawson, a researcher at the Samuel Lunenfeld Research Institute at the Mount Sinai Hospital in Toronto, says the AFCS concept is timely because scientists are starting to create their own databases of the interactions between cell-signalling molecules. But there is little coordination between them.

Pawson recently helped to launch a series of workshops under the auspices of the National Institutes of Health, the first of which was held in Washington last week. The aim is to help scientists talk to each other about where they can cooperate or merge their activities. He is talking to Gilman about how his own group's database, BIND (Biomolecular Interaction Network Database; http://bioinfo.mshri.on.ca) could cooperate, or even merge, with the AFCS databases.

Peter Seeburg, a director of the Max Planck Institute for Medical Research in Heidelberg, who studies mechanisms of action of membrane receptors, says that the initiative is "to be applauded". But because it is limited to two models, there is plenty of room for similar initiatives to be launched outside the project.

Axel Ullrich, director of the department for molecular biology at the Max Planck Institute for Biochemistry in Munich, says that the AFCS is "fantastic".

Full details of the new initiative can be found on http://afcs.swmed.edu Alison Abbott

\section{Japan calls for partnership to develop semiconductors}

Tokyo

A group of leading Japanese electronics companies has proposed a joint industry-government programme to develop next-generation semiconductor technology for the emerging system-on-achip (SoC) industry.

The proposal includes a plan to establish technical standards to enable intellectualproperty components from different sources to be mixed and matched, which is necessary for the building of custom SoCs embedded within complex systems.

The move reflects a feeling within Japan's semiconductor industry - which once dominated more than half the world market - that the recent technological and industrial shift towards logic-based products may lead to a further decline in its world share, which has dropped to 25 per cent.

The proposal was made by Semiconductor Industry Research Institute Japan (SIRIJ), an organization funded by leading Japanese semiconductor manufacturers, including Fujitsu, Hitachi, Matsushita, Mitsubishi Electric, NEC, Oki Electric Industry, Rohm, Sanyo, Sharp, Sony and Toshiba, to promote industrial research into silicon semiconductor technology.

The programme would involve all the companies involved in SIRIJ, and is expected to obtain support from the Ministry of

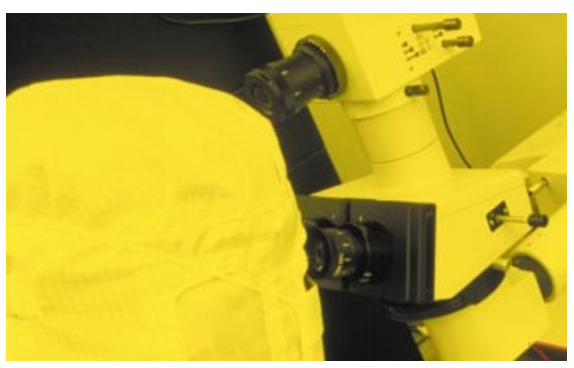

Looking for integration: Japanese companies want to work with government to develop chips.

International Trade and Industry (MITI) to set up a core research centre in 2001.

The programme would be modelled on Project Alba in Scotland, which brought together Scottish Enterprise - a government economic development body — and universities and industry from both within and outside Scotland to promote the research and development (R\&D) of SoC technology.

Although MITI says that the proposal is "not yet on the official agenda", industry sources say the plan is expected to be finalized by the end of this year and to be announced officially next spring.

"The Japanese semiconductor industry was slow to respond to paradigm changes in both technology and the market, as well as intensifying competition from Asian and US companies," says Tsuguo Makimoto, former director of Hitachi, who was instrumental in drawing up the proposal. Makimoto points out that Japan became too complacent about its dominance in memory-based technology, such as DRAM chips, in the 1980s. As a result, it "made very little effort in R\&D for semiconductor technology for nearly a decade, while the rest of the world moved on".

As the global semiconductor industry makes a shift towards highly integrated devices for digital information products, the development of SoC technology, which enables complex systems to be put onto a single piece of silicon, is seen as crucial.

Over the next five years, advances in technology may allow up to 200 million transistors to be placed on a single chip, yet few companies have the intellectual property or technology to use this capacity.

"In addition to legal and technological challenges, the lack of adequate human resources is a serious problem for the Japanese semiconductor industry," says Makimoto.

He says that Japan needs an organization similar to the US Semiconductor Technology Council to oversee policies in semiconductor research, as well as a central institution to promote joint industry-university research and to design new curricula at universities. "In short, we have to forget our past glories and start everything from scratch," says Makimoto.

Asako Saegusa 